\title{
Association between Dialysis Dose Improvement and Nutritional Status among Hemodialysis Patients
}

\author{
Ahmad T. Azar ${ }^{a} \quad$ Khaled Wahba $^{\mathrm{b}}$ Abdalla S.A. Mohamed ${ }^{\mathrm{b}}$ Waleed A. Massoud $^{\mathrm{c}}$ \\ a Biomedical Engineering, HTI, 10th of Ramadan City, and bepartment of Systems and Biomedical Engineering, \\ Cairo University, Giza, ' Nephrology Department, Ahmad Maher Teaching Hospital, Cairo, Egypt
}

\section{Key Words}

Hemodialysis • Dialysis adequacy Kt/V • Nutrition

\begin{abstract}
Background: Several studies suggest an association between improved survival and better nutritional status. It has been suggested that there is a correlation between dose of dialysis and nutritional status. However, in spite of the current practice, there are conflicting reports regarding the relationship between dose of dialysis or malnutrition, and biochemical outcome. In this article, we will discuss the impact of dose of dialysis on nutritional status and biochemical outcome in hemodialysis patients. We will also mention the interrelationships of dialysis dose, malnutrition, and biochemical outcome with respect to these patients. Methods: Data were processed on 134 dialysis patients (mean age $48.21 \pm$ 13.38, 69 male, 65 female) on 3-times-per-week dialysis regimens. The overall study period was 3 months from June 1 , 2005 to August 31,2005 . The patients were divided into two groups: the baseline group and the intervention group. The data of the baseline group were collected in June, 2005 and the data of the intervention group were collected in August, 2005 after applying the intervention or a protocol for dialysis adequacy improvement. Results: The statistical analysis demonstrated that there was a significant improvement in
\end{abstract}

mean URR and $\mathrm{Kt} / \mathrm{V}$ from the baseline to the intervention group. The intervention group had a considerably higher rate than the baseline group for all nutritional and biochemical outcome parameters. The study showed a strong positive correlation between $\mathrm{nPCR}$ and Kt/V $(p=0.0001)$ and also a strong positive correlation between serum albumin and $\mathrm{Kt} / \mathrm{V}(\mathrm{p}=0.00001)$. No correlations were found between Kt/V and biochemical outcomes such as hemoglobin $(p=0.4922)$, calcium $(p=0.650)$, phosphate $(p=0.508)$, and phosphatase $(p=0.091)$. Conclusion: All the available evidence in hemodialysis patients confirms the close association between dialysis dose and biochemical outcome. A body of evidence also highlights the existence of relationship between malnutrition and outcome among these patients. Dose of dialysis and nutrition are considered to be interrelated.

Copyright $\odot 2007$ S. Karger AG, Basel

\section{Introduction}

Malnutrition is the main factor of morbidity and mortality among hemodialysis patients [1]. Numerous studies have documented that $20-60 \%$ of the patients on hemodialysis are malnourished [2]. The National Cooperative Dialysis Study (NCDS) was reported in 1983 and was the first effort to quantify the amount and components of

\section{KARGER}

Fax +4161306 1234 E-Mail karger@karger.ch www.karger.com

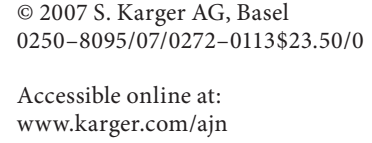

Ahmad T. Azar

Ahmad Orabi Square

Azar Building

Menouf, Menoufeya (Egypt)

Tel. +20 109418 003, Fax +20 2739 1380, E-Mail ahmad_t_azar@yahoo.com 
dialysis therapy provided to a patient and their correlation with patient outcome in a prospective randomized design [3]. The NCDS results show that protein catabolic rate (PCR; $\mathrm{g} / \mathrm{kg} /$ day) and blood urea nitrogen $(\mathrm{BUN})$ are important determinants of morbidity in patients undergoing hemodialysis. A PCR $>1 \mathrm{~g} / \mathrm{kg} / \mathrm{day}$ and a time average concentration (TAC) of BUN of approximately 50 $\mathrm{mg} / \mathrm{dl}$ were shown to be determinants of low morbidity. Several studies indicate that a low dietary protein intake as well as biochemical evidence for protein malnutrition are associated with increased morbidity and mortality [3, 4]. In the NCDS, a low PCR $(0.8 \mathrm{~g} / \mathrm{kg} /$ day $)$ was associated with treatment failure. Lowrie and Lew [5] in their more than 12,000 patients identified serum albumin concentration as the most powerful indicator of mortality. The risk of death in patients with serum albumin concentration below $2.5 \mathrm{~g} / \mathrm{dl}$ was close to 20 -fold compared to patients with serum albumin of $4.0-4.5 \mathrm{~g} / \mathrm{dl}$, which is considered to be the reference range. More importantly, when compared to this reference value, even serum albumin values of $3.5-4.0 \mathrm{~g} / \mathrm{dl}$ resulted in a twofold increase in the relative risk of death. It is important to note that this latter value of albumin is considered to be in the range of normal for many practitioners. Therefore, even a small decrease in serum albumin will cause a significant increase in mortality. In addition to serum albumin, they also defined a close relationship between mortality and other biochemical markers of nutrition. However, a low serum albumin does not always reflect a poor nutritional status of the patient. Serum albumin levels are also influenced by several other factors, such as infection, inflammation and liver diseases. It is important to note that a strong association between nutritional intake or status and clinical outcome may not indicate a causal relationship. Since, it has been shown that a comorbid condition may possibly both impair nutritional status and increase mortality independently [5]. Several studies of the relationship between dose of dialysis and outcome have been published. The results of these studies revealed that hemodialysis patient mortality showed a strong and robust inverse correlation with delivered hemodialysis dose whether measured by Kt/V or by URR [6]. Mortality risk was lower by $7 \%$ with each 0.1 higher level of delivered $\mathrm{Kt} / \mathrm{V}$. Mortality was also lower by $11 \%$ with each 5 percentage points higher URR. Above a URR of $70 \%$ or a $\mathrm{Kt} / \mathrm{V}$ of 1.3 , the data did not provide any statistically significant reductions in mortality. It appears that increasing the level of delivered dose offers a practical and efficient means of lowering the mortality rate [7, 8]. In 1989, Lindsay and Spanner [9] showed that any attempt to in- crease the protein intake in chronic kidney disease (CKD) patients undergoing hemodialysis was unsuccessful if any previous increases in the amount of prescribed hemodialysis were not established first. They also found a linear, positive correlation between Kt/V and nPCR. On the other hand, Blake et al. [10] and Yang [11] have suggested that the relationship between $\mathrm{Kt} / \mathrm{V}$ and $\mathrm{nPCR}$ is not linear, and that for a $\mathrm{Kt} / \mathrm{V}>1.7$ the $\mathrm{nPCR}$ values are flattened.

\section{Subjects and Methods}

An experimental study with a comparison group was used. The study subjects consisted of 134 hemodialysis patients on 3times-per-week dialysis regimens. No subjects dropped out of the study. The overall study period was 3 months from June 1, 2005 to August 31,2005. The patients were divided into two groups: the baseline group and the intervention group. The data of the baseline group for 134 patients were collected in June, 2005 and the re-measurement data for the same number of patients were collected in August, 2005 after applying the intervention or a protocol for dialysis adequacy improvement. The intervention plan was based on the philosophy that the cause of inadequate dialysis differs between patients. Possible root causes for inadequate dialysis include: prescription related, access related, treatment not delivered as prescribed, or patient compliance. Root cause analysis was discussed with the dialysis experts and the dialysis facility was encouraged to utilize its internal quality programs to identify the root cause and to focus intervention activity accordingly. For each patient, age, gender, height, type of vascular access, location of access, pre-weight, post-weight, type of dialysate, weight gain and HD duration were recorded. The characteristics of the patients are shown in table 1 . Special attention was paid to the real dialysis time, so that time-counters were fitted to all machines for all sessions, to record effective dialysis duration (excluding any unwanted interruptions, e.g. due to dialysis hypotensive episodes). For each dialysis session for each patient the following were recorded: BUN at beginning $\left(\mathrm{C}_{0}\right)$, and at the end $\left(\mathrm{C}_{\mathrm{t}}\right)$ of the session (latter obtained $3 \mathrm{~min}$ after slowing the pump speed to $50 \mathrm{ml} / \mathrm{min}$ ), a value which correlated extremely well with that of a sample taken 30 min after the cessation of dialysis where true dialysis time $\mathrm{T}$, the intradialytic weight loss (UF), patients' dry weight $\left(\mathrm{W}_{\mathrm{t}}\right)$, and hematological profile were obtained. Using a computer-based single-pool urea kinetic modeling program, the following parameters were determined: the hemodialysis index (Kt/V) according to the Daugirdas second-generation formula [12], the protein catabolic rate per normalized body weight (nPCR, g/kg/day), the time-averaged urea concentration (TAC, $\mathrm{mg} / \mathrm{dl}$ ), and the urea generation rate $(\mathrm{G}, \mathrm{mg} / \mathrm{min})$. The dialyzer clearance and the percent of recirculation (using the three-sample method) that were calculated for each patient by using the formulas are shown in the 'Appendix'.

Statistical analysis was performed using SPSS 10.0 and NCSS 2004 software packages. Mean errors relative to reference values were compared by one way ANOVA, with significant group differences $(p<0.05)$ localized by post-hoc application of the pair- 
Table 1. Patient characteristics

\begin{tabular}{lc}
\hline Patient characteristics & Count \\
\hline Number of patients & 134 \\
Time on HD, months & \\
$\quad$ Range & $6-96$ \\
$\quad$ Mean & $32.14 \pm 28.72$ \\
Age, years & $15-73$ \\
Range & $48.21 \pm 13.38$ \\
Mean & \\
Gender & $69(51 \%)$ \\
Male & $65(49 \%)$ \\
Female & $127-180$ \\
Height, cm & $157.46 \pm 7.15$ \\
Range & $169.54 \pm 6.07$ \\
Mean female height & \\
Mean male height & $22.3 \pm 2.25$ \\
BMI & $18.1-30.7$ \\
Mean & \\
Range & $24(18 \%)$ \\
Type of dialysate & $110(82 \%)$ \\
Bicarbonate & $123(91.8 \%)$ \\
Acetate & $11(8.2 \%)$ \\
Access type & \\
AV fistula & $22(16.42 \%)$ \\
Temporary catheter & $81(60.45 \%)$ \\
Dialyzer type and surface area & $31(23.13 \%)$ \\
1.2 ${ }^{2}$ cellulosynthetic, homophane & \\
$1.3 \mathrm{~m}^{2}$ polysulfone & \\
1.6 m $^{2}$ polysulfone & \\
\hline
\end{tabular}

wise least significant difference test. Confidence intervals on the discrepancy between different estimates of the same parameter are calculated as Bland-Altman 95\% limits of agreement. Comparison of means between the two groups was made using the paired-sample $t$ test. Comparison of variances between the two groups of results was made using the $\mathrm{F}$ test. Logistic regression analysis was used to assess the correlation between dialysis adequacy and the nutritional status parameters. The most common measure of correlation is the Pearson product moment correlation (called Pearson's correlation for short). Pearson's correlation (R) reflects the degree of linear relationship between two variables. The squared correlation coefficient is called the coefficient of determination. The coefficient of determination is one of the best means for evaluating the strength of a relationship that represents the fraction of the variation in one variable that may be explained by the other variable.

\section{Results}

The treatment characteristics before (baseline group) and after (intervention group) a quality improvement program (QIP) are shown in table 2 .

Dialysis Dose Improvement and

Nutritional Status
Table 2. Comparison of treatment characteristics between the baseline and the intervention groups

\begin{tabular}{|c|c|c|}
\hline Patient characteristics & $\begin{array}{l}\text { Baseline group } \\
\text { (pre-QIP) }\end{array}$ & $\begin{array}{l}\text { Intervention } \\
\text { group } \\
\text { (post-QIP) }\end{array}$ \\
\hline Number of patients & 134 & 134 \\
\hline Mean treatment duration, $\mathrm{h}$ & $3.61 \pm 0.38$ & $3.87 \pm 0.28$ \\
\hline \multicolumn{3}{|l|}{ Mean blood flow rate, $\mathrm{ml} / \mathrm{min}$} \\
\hline Range & $200-300$ & $200-350$ \\
\hline Mean & $268.89 \pm 36.29$ & $301.34 \pm 24.09$ \\
\hline Dialysate flow rate, $\mathrm{ml} / \mathrm{min}$ & 500 & 800 \\
\hline \multicolumn{3}{|l|}{ Predialysis weight, kg } \\
\hline Range & $35-112$ & $35.5-114$ \\
\hline Mean & $68.78 \pm 15.45$ & $70.02 \pm 15.55$ \\
\hline \multicolumn{3}{|l|}{ Interdialytic weight gain, $\mathrm{kg}$} \\
\hline Range & $0-5$ & $0-5$ \\
\hline Mean IDWG & $2.048 \pm 1.24$ & $2.52 \pm 1.18$ \\
\hline \multicolumn{3}{|l|}{ Ultrafiltration rate, $\mathrm{ml} / \mathrm{min}$} \\
\hline Range & $0.05-20.83$ & $0-26.5$ \\
\hline Mean UFR & $8.54 \pm 5.15$ & $11.36 \pm 5.48$ \\
\hline Predialysis BUN, mg/dl & $124.94 \pm 33.17$ & $129.36 \pm 33.50$ \\
\hline Postdialysis BUN, mg/dl & $52.66 \pm 15.06$ & $42.052 \pm 11.43$ \\
\hline \multicolumn{3}{|l|}{$\mathrm{Kt} / \mathrm{V}_{\mathrm{eq}}{ }^{*}$} \\
\hline Range & $0.62-1.54$ & $0.65-1.56$ \\
\hline Mean & $0.99 \pm 0.21$ & $1.21 \pm 0.17$ \\
\hline \multicolumn{3}{|l|}{ URR, \%* } \\
\hline Range & $40.33-77.77$ & $45.71-75.52$ \\
\hline Mean & $58.77 \pm 8.36$ & $65.99 \pm 5.33$ \\
\hline
\end{tabular}

From table 2, the statistical analysis demonstrated that there was a significant improvement in mean URR from the baseline to the intervention group (URR: $58.77 \pm$ 8.36 vs. $65.99 \pm 5.33$, respectively; $\mathrm{p}=0.00001)$ and also there was a significant improvement in mean Kt/V from the baseline to the intervention group (Kt/V: $0.99 \pm 0.21$ vs. $1.21 \pm 0.17$, respectively; $\mathrm{p}=0.00001$ ). It was noted that the intervention group showed a statistically significant increase of $21.24 \%$ in dialysis adequacy and $12.28 \%$ increase in URR after applying the quality improvement program. In aggregate, table 2 indicated that the factors impacting the dialysis prescription were increased in order to increase the dialysis adequacy. Figure 1 illustrates the comparison of $\mathrm{Kt} / \mathrm{V}$ and URR between the baseline and the intervention groups.

Statistical analysis demonstrated that the intervention group had a considerably higher rate than the baseline group for all nutritional and biochemical outcome parameters. For nPCR, the intervention group increased by $13.63 \%$, from 0.939 at baseline to 1.067 at remeasurement,

Am J Nephrol 2007;27:113-119 

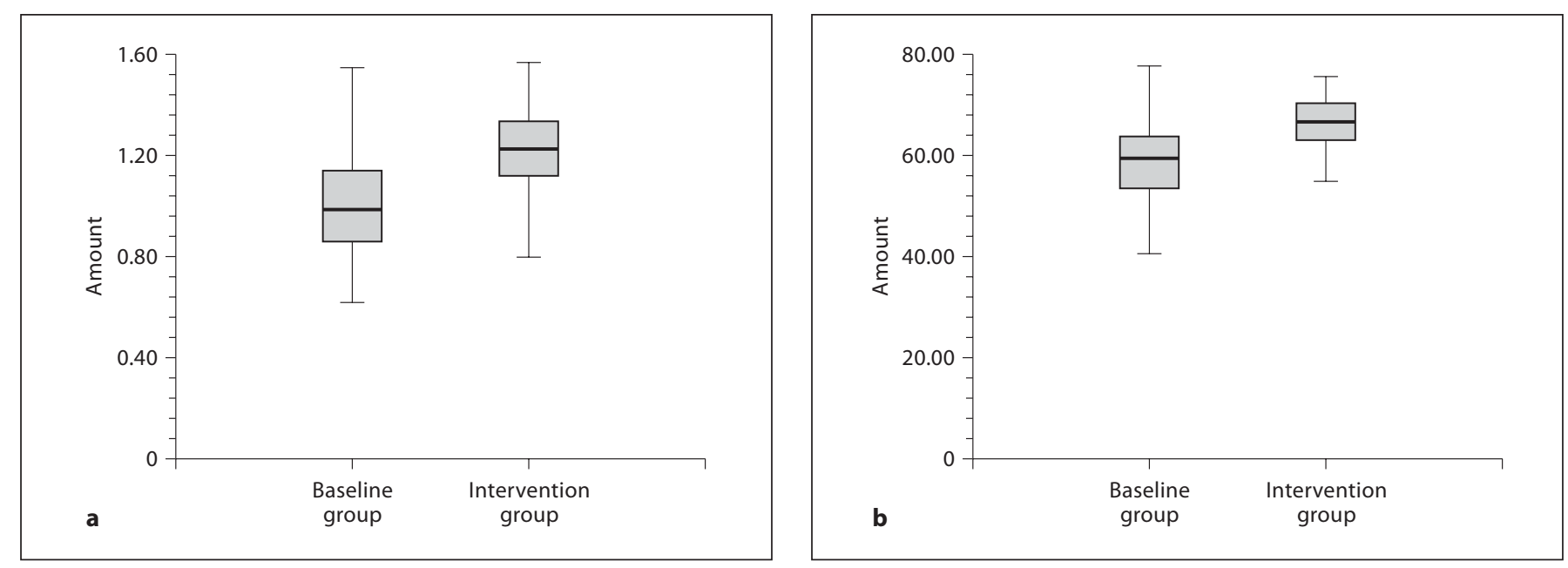

Fig. 1. a Box plot comparison of dialysis adequacy Kt/V between the baseline and intervention groups. b Box plot comparison of URR between the baseline and intervention groups.

Table 3. Nutritional status and biochemical outcome parameter comparison between the baseline and intervention groups

\begin{tabular}{|c|c|c|}
\hline $\begin{array}{l}\text { Nutritional and } \\
\text { biochemical parameters }\end{array}$ & $\begin{array}{l}\text { Baseline group } \\
\text { (pre-QIP) }\end{array}$ & $\begin{array}{l}\text { Intervention group } \\
\text { (post-QIP) }\end{array}$ \\
\hline \multicolumn{3}{|l|}{ nPCR, g/kg/day } \\
\hline Range & $0.437-1.26$ & $0.73-1.28$ \\
\hline Mean & $0.939 \pm 0.125$ & $1.067 \pm 0.101$ \\
\hline \multicolumn{3}{|l|}{ Albumin, g/dl } \\
\hline Range & $1.9-4.2$ & $2.4-5.6$ \\
\hline Mean & $3.218 \pm 0.380$ & $3.76 \pm 0.46$ \\
\hline \multicolumn{3}{|l|}{ Hemoglobin, g/dl } \\
\hline Range & $5.3-12.4$ & $4.5-14.5$ \\
\hline Mean & $8.45 \pm 1.424$ & $9.196 \pm 1.95$ \\
\hline \multicolumn{3}{|l|}{ Calcium, mg/dl } \\
\hline Range & $4.6-11.7$ & $6.1-11.9$ \\
\hline Mean & $8.56 \pm 1.02$ & $9.038 \pm 0.875$ \\
\hline \multicolumn{3}{|l|}{ Phosphate, mg/dl } \\
\hline Range & $1.5-10.9$ & $2.2-12.3$ \\
\hline Mean & $5.93 \pm 1.943$ & $6.81 \pm 1.84$ \\
\hline \multicolumn{3}{|l|}{ Phosphatase, IU/1 } \\
\hline Range & 38-927 & $41-888$ \\
\hline Mean & $186.36 \pm 154.86$ & $217.19 \pm 148.97$ \\
\hline
\end{tabular}

which was a statistically significant increase $(\mathrm{p}=0.00001)$ and was a statistically significant variance difference $(\mathrm{F}=1.532$ with $\mathrm{p}=0.0145)$. For serum albumin, the intervention group increased by $16.81 \%$, from 3.218 at baseline to 3.759 at remeasurement, which was a statistically significant increase $(\mathrm{p}=0.00001)$ and was a statisti- cally significant variance difference $(\mathrm{F}=1.497$ with $\mathrm{p}=$ 0.021 ). For hemoglobin, the intervention group increased by $8.83 \%$, from 8.45 at baseline to 9.196 at remeasurement, which was a statistically significant increase $(\mathrm{p}=$ 0.00043 ) and a statistically significant variance difference $(F=1.876$ with $p=0.0003)$. For calcium, the intervention group increased by $5.58 \%$, from 8.56 at baseline to 9.038 at remeasurement, which was a statistically significant increase $(\mathrm{p}=0.00006)$ but there was no statistically significant variance difference between the two groups $(\mathrm{F}=1.359$ with $\mathrm{p}=0.08)$. For phosphate, the intervention group increased by $14.83 \%$, from 5.93 at baseline to 6.81 at remeasurement, which was a statistically significant increase $(p=0.000187)$ but there was no statistically significant variance difference between the two groups $(\mathrm{F}=1.115$ with $\mathrm{p}=0.531)$. There was no statistically significant increase in phosphatase $(\mathrm{p}=0.0979)$ between the intervention and the baseline groups and neither was there a statistically significant variance difference between the two groups ( $\mathrm{F}=1.081$ with $\mathrm{p}=0.655)$. These statistical analyses reveal that the nutritional status of patients was improved due to the improvement in dialysis adequacy and session performance. Table 3 summarizes a comparison of the nutritional status and biochemical outcome parameters between the baseline and the intervention groups.

Correlation between dialysis adequacy, nutritional status and biochemical outcome of patients was studied by linear regression analysis and analysis of variance (ANOVA) and are shown in table 4. No correlations were 


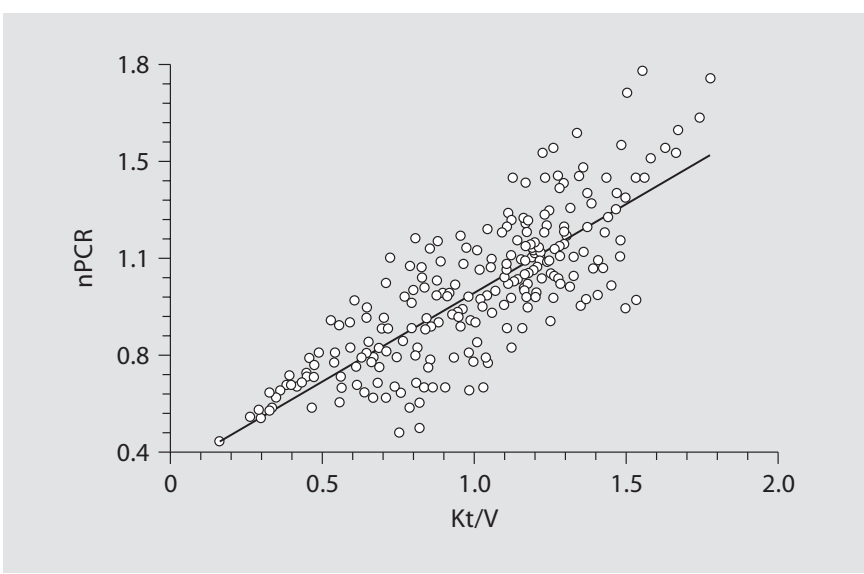

Fig. 2. Plots of nPCR versus Kt/V; 248 observations on hemodialysis patients.

found between $\mathrm{Kt} / \mathrm{V}$ and biochemical outcomes such as hemoglobin $(\mathrm{p}=0.492)$, calcium $(\mathrm{p}=0.650)$, phosphate $(\mathrm{p}=0.508)$, and phosphatase $(\mathrm{p}=0.091)$. Regression analysis revealed that there is a strong positive correlation between dialysis adequacy Kt/V and normalized protein catabolic rate (nPCR). The equation of the straight line relating $\mathrm{nPCR}$ and $\mathrm{Kt} / \mathrm{V}$ using 248 observations in the dataset is estimated as:

$$
\mathrm{nPCR}=0.3402+(0.6397 \cdot \mathrm{Kt} / \mathrm{V})
$$

The y-intercept, the estimated value of nPCR when $\mathrm{Kt} / \mathrm{V}$ is zero, is 0.3402 with a standard error of 0.0316 . The slope, the estimated change in nPCR per unit change in $\mathrm{Kt} / \mathrm{V}$, is 0.6397 with a standard error of 0.0297 . The value of $\mathrm{R}$-squared, the proportion of the variation in $\mathrm{nPCR}$ that can be accounted for by variation in $\mathrm{Kt} / \mathrm{V}$, is 0.6537 . The correlation between $\mathrm{nPCR}$ and $\mathrm{Kt} / \mathrm{V}$ is 0.8085 . A significance test that the slope is zero resulted in a $t$ value of 21.5482 . The significance level of this $t$ test is 0.0001 . Since 0.0001 is $<0.05$, the hypothesis that the slope is zero is rejected. The relationship between $\mathrm{Kt} / \mathrm{V}$ and $\mathrm{nPCR}$ is shown is figure 2 .

Regression analysis also revealed that there is a strong positive correlation between dialysis adequacy $\mathrm{Kt} / \mathrm{V}$ and serum albumin $\left(\mathrm{R}=0.8145\right.$ and $\left.\mathrm{R}^{2}=0.6634\right)$. The equation of the straight line relating albumin and $\mathrm{Kt} / \mathrm{V}$ using 134 observations in the dataset is estimated as:

$$
\text { Albumin }=0.3450+(2.6852 \cdot \mathrm{Kt} / \mathrm{V}) \text {. }
$$

A significance test that the slope is zero resulted in at value of 16.1309. The significance level of this $t$ test is

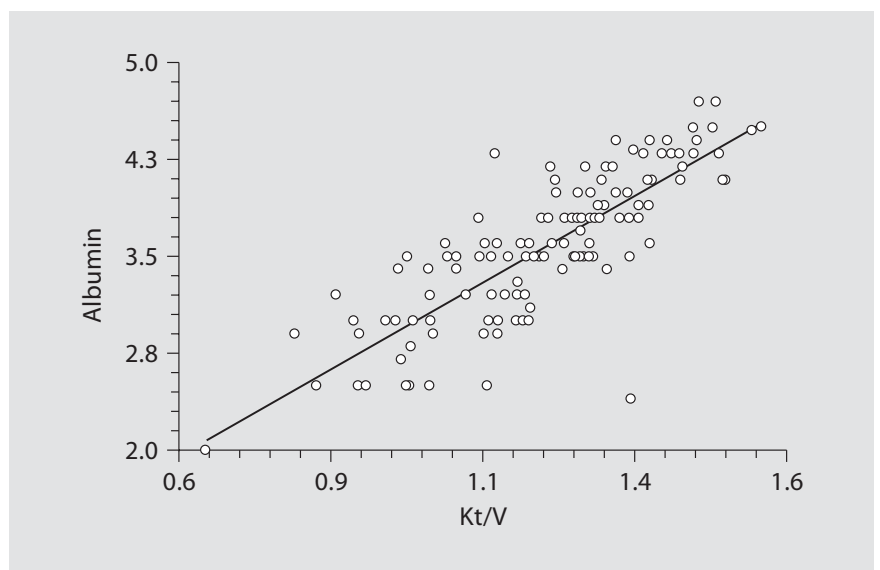

Fig. 3. Plots of serum albumin versus Kt/V. A strong positive correlation was observed between $\mathrm{Kt} / \mathrm{V}$ and serum albumin levels.

Table 4. Correlation and regression analysis results between dose

\begin{tabular}{|c|c|c|c|c|c|c|}
\hline & nPCR & Albumin & $\mathrm{Hb}$ & $-\mathrm{Ca}$ & $\mathrm{Ph}$ & Alp \\
\hline $\mathrm{R}$ & 0.808 & 0.815 & 0.06 & -0.04 & 0.06 & 0.15 \\
\hline $\mathrm{R}^{2}$ & 0.654 & 0.663 & 0.004 & -0.002 & 0.004 & 0.023 \\
\hline \multicolumn{7}{|c|}{ Standard error } \\
\hline \multicolumn{7}{|c|}{ Regression values } \\
\hline A & 0.64 & 2.69 & 0.699 & -0.21 & 0.80 & 143.3 \\
\hline B & 0.34 & 0.35 & 8.36 & -9.22 & 5.42 & 41.27 \\
\hline t value & 21.55 & 16.13 & 0.69 & -0.46 & 0.67 & 1.71 \\
\hline $\mathrm{p}$ value & 0.0001 & 0.00001 & 0.492 & -0.650 & 0.508 & 0.09 \\
\hline
\end{tabular}
of dialysis and nutritional parameters

0.00001 . Since 0.00001 is $<0.05$, the hypothesis that the slope is zero is rejected. The relationship between $\mathrm{Kt} / \mathrm{V}$ and serum albumin is shown is figure 3 .

Table 4 summarizes the regression analysis that was made between dialysis dose $\mathrm{Kt} / \mathrm{V}$ versus nutritional and clinical outcome parameters.

\section{Discussion}

According to protein indicators, it seems likely that life-threatening malnutrition is present in about $25 \%$ of hemodialysis patients. The recent NKF-DOQI recommendation for dietary protein intake in maintenance hemodialysis patients is $1.2 \mathrm{~g} / \mathrm{kg}$ body weight/day. The rec- 
ommended daily energy intake for maintenance hemodialysis patients is $35 \mathrm{kcal} / \mathrm{kg}$ BW/day for those who are less than 60 years of age, and $30-35 \mathrm{kcal} / \mathrm{kg}$ for individuals 60 years of age or older. Only $35 \%$ of our patients are eating between 1.07 and $1.32 \mathrm{~g}$ of protein/kg/day. We considered those patients with nPCR values below $0.8 \mathrm{~g} / \mathrm{kg} / \mathrm{day}$ as high-risk patients. Consequently, when we were not able to modify their nutritional status with dietary counseling we used aggressive dietary intervention, which included the use of oral dietary supplements, a nasogastric tube feeding, placement of a PEG tube in gastroparetic patients, and the use of intradialytic parenteral nutrition in selected patients. To design an optimal therapy for dialysis, we plotted nPCR and predialysis BUN. In our dialysis unit, we have progressively increased the dose of dialysis to a $\mathrm{Kt} / \mathrm{V}$ of 1.4. Patients who are under-dialyzed lose their appetite and may develop malnutrition.

The statistical analysis of the relationship between the $\mathrm{nPCR}$ and the dialysis adequacy, as expressed by $\mathrm{Kt} / \mathrm{V}$, showed a positive correlation. The study showed a strong positive correlation between $\mathrm{nPCR}$ and $\mathrm{Kt} / \mathrm{V}$ and also a strong positive correlation between serum albumin and $\mathrm{Kt} / \mathrm{V}$. We also found a positive, although not statistically significant, correlation between nPCR and serum albumin levels $(R=0.41, p=0.22)$. The finding suggests that the correlation between $\mathrm{nPCR}$ and $\mathrm{Kt} / \mathrm{V}$ is linear and the improvement of the nutrition of patients undergoing chronic hemodialysis is closely related to the amount of hemodialysis delivered to those patients. This finding suggests also that patients undergoing chronic hemodialysis adjust their protein intake automatically according to the dose of hemodialysis delivered, probably via an improvement in appetite as a result of the disappearance of uremic symptoms from the digestive system (e.g. nausea, anorexia, vomiting). The increase in protein intake causes an increase in urea production, manifested as an increase in TAC, which we observed in our patients. This implies that patients with high predialysis urea concentrations (in the absence of neoplasia, infection, hyperthyroidism, etc.) are those treated with the higher hemodialysis dose, and, as a consequence, present the higher nPCR values. According to the NCDS criteria, these patients manifest lower morbidity and mortality rates.

In our study, the programmed increase of hemodialysis dose in 7 patients resulted in the concomitant increase of the nPCR, although no attempt was made to alter the usual dietary habits of our patients. Our finding also suggests that patients with a lower protein intake show a propensity towards obesity, which seems somewhat peculiar. The possible explanation that we can suggest is that patients with CKD are known to be insulin resistant, a situation that is accompanied by obesity. Therefore, we can suggest that the usual hemodialysis dose, when coupled with nPCR values $<1.4 \mathrm{~g} / \mathrm{kg} /$ day, is insufficient to correct the metabolic disturbance of insulin resistance observed in these patients and, thus, they exhibit a propensity toward obesity.

Recirculation was another factor found to influence the nPCR values. The method used to estimate the recirculation was the 'three-sample method' using arterial, venous, and peripheral blood. Although recirculation determined by this method is considered by some to be an artifact, we found that 13 of our patients had a recirculation fraction greater than zero $(5.22 \pm 6.26 \%)$. The correlation between $\mathrm{nPCR}$ and recirculation was negative $(\mathrm{R}=-0.59, \mathrm{p}=0.01) . \mathrm{Kt} / \mathrm{V}$ was also found to be negatively correlated with recirculation, though the correlation was not statistically significant $(\mathrm{R}=-0.29, \mathrm{p}=$ $0.45)$. This finding suggests that if the recirculation fraction, as estimated by the three-sample method, is capable of influencing two other independent variables (nPCR and Kt/V) in the same direction, then it is wise to assume that it is not an artifact. This would, at least, be the case with regard to the use of standard dialyzers, where the 'rebound phenomenon' is not so evident and the equilibrium between the peripheral microcirculation and the central pool blood is feasible during the usual hemodialysis time.

\section{Acknowledgements}

The author thanks all the medical staff at the Nephrology Department in Ahmad Maher Teaching Hospital, Cairo, Egypt, for their invaluable support during the course of this study. 


\section{Appendix}

\section{Recirculation $(\%)=$}

$\left(\left(\mathrm{C}_{\text {peripheral }}-\mathrm{C}_{\text {art }}\right) /\left(\mathrm{C}_{\text {peripheral }}-\mathrm{C}_{\mathrm{ven}}\right)\right) \times 100$

where $\mathrm{C}_{\mathrm{p}}=$ peripheral BUN or stop-flow, $\mathrm{C}_{\text {art }}=$ dialyzer inlet (arterial), and $\mathrm{C}_{\mathrm{ven}}=$ dialyzer outlet (venous).
Dialyzer clearance measured by AV gradient method (diffusion + ultrafiltration)

$$
\mathrm{K}=\mathrm{Q}_{\mathrm{B}}\left(\left(\mathrm{C}_{\mathrm{Bi}}-\mathrm{C}_{\mathrm{Bo}}\right) / \mathrm{C}_{\mathrm{Bi}}+\mathrm{Q}_{\mathrm{F}}\left(\mathrm{C}_{\mathrm{Bo}} / \mathrm{C}_{\mathrm{Bi}}\right) \quad \mathrm{ml} / \mathrm{min}\right.
$$

Diffusive term Convective term

where $\mathrm{K}$ = dialyzer clearance, $\mathrm{Q}_{\mathrm{B}}=$ blood flow rate, $\mathrm{C}_{\mathrm{Bi}}=$ urea concentration at the dialyzer inlet, $\mathrm{C}_{\mathrm{Bo}}=$ urea concentration at the dialyzer outlet, and $\mathrm{Q}_{\mathrm{F}}=$ ultrafiltration rate.

\section{References}

1 Acchiardo SE, Moore LW, Latour PA: Malnutrition as the main factor in morbidity and mortality of hemodialysis patients. Kidney Int 1983;24:S199-S203.

2 Dwyer JT, Cunniff PJ, Maroni BJ, Kopple JD, Burrows JD, Powers SN, et al: The Hemodialysis (HEMO) pilot study: nutrition program and participant characteristics at baseline. J Renal Nutr 1998;8:11-20.

3 Harter HR: Review of significant finding from the NCDS and recommendations. Kidney lnt 1983;23(suppl 13):10712.

4 Marckmann P: Nutritional status and mortality of patients in regular dialysis therapy. Lint Med 1989;226:429-432.
5 Lowrie EG, Lew NL: Death risk in hemodialysis patients: the predictive value of commonly measured variables and an evaluation of death rate differences between facilities. Am J Kidney Dis 1990;15; 458-482.

6 Owen WF, Lew NL, Lieu Y, Lowrie EG, Lazarus $1 \mathrm{M}$ : The urea reduction ratio and serum albumin concentration as predictors of mortality in patients undergoing hemodialysis. N Engl J Med 1993;329:1001-1006.

7 Hakim RM, Breyer J, Ismail N, Schulman G: Effects of dose of dialysis on morbidity and mortality. Am J Kidney Dis 1994;23:661669.

8 Lindsay RM: The influence of dialysis prescription and nutritional status on outcome of dialysis patients. Nefrologia 1994;14:2531 .
9 Lindsay RM, Spanner E: A hypothesis: the protein catabolic rate is dependent upon the type and amount of treatment in dialyzed uremic patients. Am J Kidney Dis 1989;5: 382-389.

10 Blake P, Lindsay RM. Spanner E, et al: The relationship between $\mathrm{Kt} / \mathrm{V}$ and normalized protein catabolic rate (nPCR) is not linear. Perit Dial Int 1993;13(suppl 1):S71.

11 Yang CS: Dose of dialysis and nutrition in hemodialysis patients: association with clinical outcome. Acta Nephrol 1997;11:66-70.

12 Daugirdas JT: Second generation logarithmic estimates of single-pool variable volume $\mathrm{Kt} / \mathrm{V}$ : an analysis of error. J Am Soc Nephrol 1993;4:1205-1213. 